\title{
Cytochrome P450 2D6 phenotype and genotype in hypertensive patients on long-term therapy with metoprolol
}

\author{
Duricova $\mathrm{J}^{1}$, Perinova $\mathrm{I}^{1}$, Jurckova $\mathrm{N}^{2}$, Jeziskova $\mathrm{I}^{2}$, Kacirova $\mathrm{I}^{1}$, Grundmann $\mathrm{M}^{1}$ \\ Department of Clinical Pharmacology Faculty of Medicine University of Ostrava and University Hospital Ostrava, \\ Czech Republic. jana.duricova@fno.cz
}

\begin{abstract}
Objective: The aim was to compare cytochrome P450 2D6 phenotype and genotype using metoprolol as a probe drug. Further, to investigate the influence of P450 2D6 activity on metoprolol pharmacokinetics and pharmacodynamics in patients on metoprolol therapy.

Background: Cytochrome P450 2D6 is a highly polymorphic enzyme that contributes to the variability of metoprolol. However, environmental factors also modify drug disposition.

Methods: Forty-nine hypertensive patients were enrolled. Serum metoprolol and a-hydroxymetoprolol concentrations, resting heart rate were measured before, 1, 3 and 4 hours post-dose.

Results: Significantly higher normalized metoprolol serum concentrations, normalized metoprolol $\mathrm{AUC}_{0-4}$ and metoprolol oral clearance were observed in patients with lower P450 2D6 metabolic activity. A trend towards a lower resting heart rate before metoprolol intake was also observed in this group of patients. The differences in metoprolol disposition were more expressed when P450 2D6 phenotype instead of genotype was determined. Conclusion: Significant variations exist in metoprolol disposition in hypertensive patients. Both genotyping and phenotyping provides a valuable method in determining the enzymatic activity and in optimising metoprolol therapy (Tab. 3, Fig. 8, Ref. 35). Full Text in PDF www.elis.sk.

Key words: metoprolol, cytochrome P450 2D6, genotype, phenotype.
\end{abstract}

The cytochromes P450 (P450) are the superfamily of hemecontaining monooxygenases playing an important role in the biotransformation of both endogenous and exogenous compounds (1). Most human P450s that participate in drug metabolism show a considerable interindividual variability in most humans in both levels of expression and catalytic activity. This variability is due to both environmental and genetic factors (2). P450 2D6 (known as debrisoquine/sparteine hydroxylase) is a highly polymorphic enzyme (3). To date, more than 100 different P450 2D6 allelic variants and sub-variants have been defined (4). In general, genotypes may be differentiated into four subgroups: poor (PM), intermediate (IM), extensive (EM) and ultrarapid (UM) metabolizers. Subjects with a PM genotype lack any functional allele, whereas EMs have two and UM subjects have more than two functional alleles. Subjects with IM genotype are heterozygous for a specific variant allele and/or possess alleles with reduced activity (4). The frequency of individual variants of P450 2D6 shows a marked interethnic difference. In white European populations, the percentage of PM varies from $3.2 \%$ (Finish) to $11.7 \%$ (Germans), but PMs constitute less than $1 \%$ of Asian subjects $(6,7)$. Beside the

\footnotetext{
${ }^{1}$ Department of Clinical Pharmacology Faculty of Medicine University of Ostrava and University Hospital Ostrava, Czech Republic, and ${ }^{2}$ Department of Medical Genetics University Hospital Ostrava, Czech Republic

Address for correspondence: J. Duricova, Department of Clinical Pharmacology, University Hospital Ostrava. 17. listopadu 1790, CZ-708 52 Ostrava, Czech Republic.

Phone: +420.597372289 , Fax: +420.597374393
}

genetic variability, environmental factors such as dietary habits (8) or drug interactions may also modify drug disposition (9). In vivo P450 phenotyping has proven to be very successful in predicting the actual enzymatic activity. It is based on administration of an adequate probe drug followed by measurement and calculation of metabolic ratio (MR) of a parent compound to its metabolite mediated by $\mathrm{P} 450$ of interest. The MR of $\mathrm{P} 450$ 2D6 probe drugs shows bimodal or even trimodal distribution - the EM, (IM) and PM subgroups. Metoprolol serves as one of the probe drugs, with 70-80\% of its metabolism mediated by P450 2D6, of which $\alpha$-hydroxylation seems to be exclusively mediated by P450 2D6 $(10,11)$.

Genetic plymorphism in cytochrome P450 2D6 (P450 2D6) has been demonstrated to contribute to the variability of several beta-blockers. Cytochrome P450 2D6 contributes mainly to the metabolism of $\beta 1$ selective blocker metoprolol (12). Single dose studies and studies with repeated dosing demonstrated that plasma concentrations of metoprolol were higher in patients with reduced enzyme activity. A 6-fold difference in metoprolol availability has been observed between the EMs and PMs. The elimination halflife was much longer in PMs than in EMs. Additionally, studies indicated that PMs experience enhanced or prolonged $\beta$-blockade compared to EMs (13-17). Thus, patients treated with metoprolol might have a quite different cardiovascular responsiveness, depending on their P450 2D6 genotype. PM genotype might be even associated with a higher incidence of metoprolol-associated adverse effects $(18,19)$.

The aim of the present study was to compare P450 2D6 phenotype with P450 2D6 genotype using metoprolol as a probe drug. 
Secondly, we investigated the influence of P450 2D6 metabolic activity on pharmacokinetics and pharmacodynamics of metoprolol in our hypertensive patients on routine treatment with metoprolol.

\section{Methods}

\section{Subjects and study protocol}

Forty-nine adult patients ( 33 females), attending an outpatient clinic for hypertension treatment in our department, were included. The median age was 58 years (21-86), median body weight was $82 \mathrm{~kg}(51-149)$. The patients were on routine treatment with metoprolol succinate (Betaloc ZOK, AstraZeneca, UK) and metoprolol tartrate (Betaloc SR, AstraZeneca, UK; Vasocardin, Zentiva, Slovak Republic; Apo-Metoprolol, Apotex Europe BV, Netherlands; Emzok, Ivax Pharmaceuticals, Czech Republic) at doses between 50-200 mg per day. The indication for treatment was hypertension. There were no dosage changes for at least 2 weeks before blood sampling. The dosage was based solely on clinical grounds and no titration to the maximally tolerated dose was attempted. Five patients ( $11 \%$ ) were on metoprolol monotherapy, nine patients (18 $\%$ ) had one additional antihypertensive drug, nine patients (18\%) had two additional antihypertensive drugs, eleven patients (23\%) were treated by three other antihypertensive agents, nine patients (18\%) by four additional antihypertensive drugs, four patients ( $8 \%$ ) by five and two patients (4\%) by six additional antihypertensive drugs. Antagonists of renin-angiotensin-aldosterone were used by thirty-five patients ( $71 \%$ ), calcium channel blockers by twenty-nine patients $(59 \%)$, diuretics were used by twenty-one patients $(43 \%)$ and central antihypertensive agents by twenty patients $(41 \%)$. Baseline data including renal function test (serum creatinine, urea) and liver function test (ALT, AST, $\gamma$-GT) were obtained either on the day of blood sampling or within 3 months prior to the patient visit. Patients' medical history other than antihypertensive medication was recorded and screened for the presence of P450 2D6 inhibitor.

Patients were retained in the ward for a half-a-day. After an overnight fasting, blood samples ( $5 \mathrm{ml}$ each) were drawn into a neutral tube before and at 1, 3 and 4 hours after metoprolol intake. Serum was separated immediately and samples were frozen and stored at $-20{ }^{\circ} \mathrm{C}$ until processing. In addition, after a written informed consent, $5 \mathrm{ml}$ of venous blood was taken into EDTA tube for DNA extraction. The patients were instructed to take other "morning" medications (if they were on poly-therapy) at home on the study day. The patients were asked to refrain from coffee drinking throughout the day, breakfast was not allowed until 1 hour after the drug intake. Heart rate was recorded on a 10-lead resting ECG. Blood pressure was measured twice with a mercury sphygmomanometer after a 5-min rest in a sitting position and the second measurement was taken. Blood pressure and heart rate were measured before metoprolol intake and before each blood sample was taken.

In the second part of the study, thirty patients ( 21 females) were chosen to assess the impact of P450 2D6 genotype and phenotype on metoprolol pharmacokinetics and pharmacodynamics. These patients were treated with the same metoprolol preparation
(Betaloc SR) and they were not treated with medication known to inhibit P450 2D6.

\section{Assay of metoprolol and $\alpha$-hydroxymetoprolol}

Serum concentrations of metoprolol and $\alpha$-hydroxymetoprolol were measured by high-performance liquid chromatography (HPLC) with fluorescence detection at 230-300 nm, as described previously (20). Briefly, metoprolol and $\alpha$-hydroxymetoprolol were separated from $200 \mu \mathrm{l}$ serum with $50 \mu \mathrm{l} 1 \mathrm{M} \mathrm{NaOH}$ following by extraction with $1.5 \mathrm{ml}$ of dichloromethane. The mobile phase consisted of acetonitrile : methanol : water : TEA (15:5:80: 0.1, pH 3.0). Column Supercosil ${ }^{\mathrm{TM}}$ LC-18 (15 cm x 3mm, $\left.5 \mu \mathrm{m}\right)$ was used. Flow rate was $0.7 \mathrm{ml} / \mathrm{min}$. Nadolol was used as an internal standard. After evaporation, the analyte was dissolved in $20 \mu \mathrm{l}$ of methanol and $50 \mu \mathrm{l}$ of water and $20 \mu \mathrm{l}$ was injected on the column.

\section{Genotyping of P450 2D6}

Total genomic DNA was isolated from peripheral blood using the Gentra Puregene Blood Kit (Qiagene, Hilden, Germany). Genetic polymorphism of P450 2D6 was detected by PCR followed by melting curve analysis in LightCycler 1.5 Instrument (Roche, Nutley, United States). Three allelic variants of P450 2D6 - *3 (4168delA), *4 (G3465A) and *6 (3326delT) were analysed. Genotyping of P450 2D6*3 and *4 allelic variants was performed using LightMix Kits - mixtures of primers and probes designed by TIB MOLBIOL (Berlin, Germany). P450 2D6*6 allelic variant was genotyped using primers and probes as described previously (21). PCR reaction mixture was performed in a volume of $10 \mu$ l. PCR conditions were as follows: 15 minutes at $95^{\circ} \mathrm{C}$, followed by target amplification via 40 cycles of 0 seconds at $95^{\circ} \mathrm{C}$ (denaturation), 10 seconds at $55^{\circ} \mathrm{C}$ (annealing) and 40 seconds at $72{ }^{\circ} \mathrm{C}$ (extension). Subsequent melting curve analysis was performed by heating at $95{ }^{\circ} \mathrm{C}$ for 1 second, followed by cooling at $60{ }^{\circ} \mathrm{C}$ for 20 seconds and $52{ }^{\circ} \mathrm{C}$ for 20 seconds and gradual heating $\left(0,3{ }^{\circ} \mathrm{C} / \mathrm{s}\right)$ up to $85^{\circ} \mathrm{C}$. Final cooling step was at $40{ }^{\circ} \mathrm{C}$ for 30 seconds. Melting temperatures of the homozygous wildtype $\mathrm{P} 450$ $2 \mathrm{D} 6 * 3, * 4$ and $* 6$ alleles were $58.1^{\circ} \mathrm{C}, 56^{\circ} \mathrm{C}$ and $65^{\circ} \mathrm{C}$. Melting temperatures of the homozygous mutant genotypes were $51^{\circ} \mathrm{C}$, $64.3{ }^{\circ} \mathrm{C}$ and $70^{\circ} \mathrm{C}$, respectively.

\section{Data and statistical analysis}

Data are expressed as the median and range. P450 2D6 phenotype was determined using serum metoprolol/ $\alpha$-hydroxymetoprolol metabolic ratio (MR) at 3 hours post-dose. The antimode value distinguishing between EMs and PMs was set at MR $=10.5$, in agreement with literature (22). The area under the plasma concentration vs. time curve (AUC) between 0 and 4 hours was calculated according to the standard trapezoidal rule. The oral clearance was estimated using the expression: dose per $\mathrm{kg} /$ metoprolol serum concentration. For differences between groups, the nonparametric Mann-Whitney test was used. Prevalence of allele frequencies between the study results and Czech population was compared by the Fischer's exact test. A value of $\mathrm{p}<0.05$ was considered statistically significant. Statistical analysis was performed using the GraphPad Prism for Windows version 5.0 (GraphPad Prism Software, Inc). 
Tab. 1. Frequency of P450 2D6 defective alleles in our patients and in Czech population (23).

\begin{tabular}{|c|c|c|c|c|}
\hline P450 2D6 alleles & $\begin{array}{l}\text { Number of alleles } \\
\text { in our patients }\end{array}$ & $\begin{array}{l}\text { Frequency in our } \\
\text { patients }(\%)\end{array}$ & $\begin{array}{l}\text { Frequency in Czech } \\
\text { population }(\%)\end{array}$ & $\begin{array}{l}\text { Significance } \\
\text { (p value) }\end{array}$ \\
\hline *3 & 4 & 4.1 & 1.1 & $\mathrm{NS}(\mathrm{p}=0.0601)$ \\
\hline$* 4$ & 15 & 15.3 & 22.9 & $\mathrm{NS}(\mathrm{p}=0.1049)$ \\
\hline *6 & 1 & 1.0 & 0.2 & $\mathrm{NS}(\mathrm{p}=0.3281)$ \\
\hline
\end{tabular}

\section{Results}

\section{Part one}

Genotype

Distribution of P450 2D6 alleles is shown in the Table 1. There was no significant difference in the frequency of any of the alleles between the patients studied and the population in Czech Republic (23). Eighteen patients (37\%) were heterozygous for defective alleles. One patient was genotyped as a PM P450 2D6*4/*4. Fifteen patients were found to be carriers of one P450 2D6*4 defective allele, four patients were heterozygous for P450 2D6*3 allele and one patient was heterozygous for defective allele P450 2D6*6 allele. P450 2D6*1 was assumed to be present, when none of the above variant alleles had been identified.

\section{Phenotype}

Forty-six patients were phenotyped as EMs. A great variability in MR metoprolol/ $\alpha$-hydroxymetoprolol was observed in EMs, ranging from 0.13 to 8.33 . Three patients were phenotyped as PMs. One of these PMs was also a PM determined by genotyping (P450 2D6*4/4). The second patient was genotyped as a heterozygote for the defective allele P450 2D6*4 and in the third patient, no defective allele was detected. In these two patients, an inhibitor of P450 2D6 activity was included in the medication (an antiarrhythmic agent propafenone and an antidepressive agent sertraline). Inhibitors of P450 2D6 activity were further prescribed in two patients phenotyped as EMs. One of these patients was heterozygous for $\mathrm{P} 4502 \mathrm{D} 6 * 4$ defective allele, the patient was taking antidepressive agent fluoxetine and her MR was 8.33 which was close to the antimode. The second EM patient was taking

Tab. 2. Metoprolol and normalized metoprolol serum concentrations (metoprolol serum concentration/dose per $\mathrm{kg}$ ) before and 1, 3, 4 hours after metoprolol intake (median and range).

\begin{tabular}{lcc}
\hline & $\begin{array}{c}\text { Metoprolol concentrations } \\
(\mathrm{ng} / \mathrm{ml})\end{array}$ & $\begin{array}{c}\text { Normalized metoprolol } \\
\text { concentrations }\end{array}$ \\
\hline before & $12.9(0-231.4)$ & $9.0(0-100.1)$ \\
1 hour & $55.5(23.9-316.2)$ & $31.5(12.3-136.8)$ \\
3 hours & $108.1(30.4-515.5)$ & $56.3(22.5-223.0)$ \\
4 hours & $93.4(35.4-530.6)$ & $56.4(18.0-229.5)$ \\
\hline
\end{tabular}

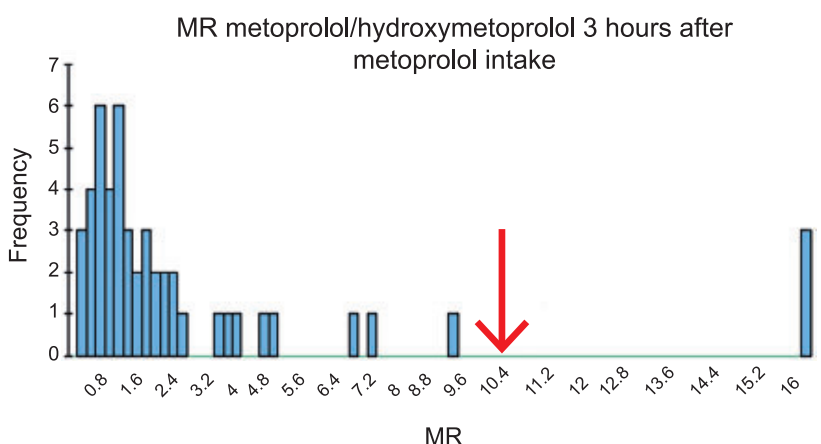

MR

Fig. 1. Distribution of metoprolol/a-hydroxymetoprolol MR in our patients. A red arrow - shows the antimode 10.5 distinguishing between EMs and PMs.

antidepressive agent sertraline, no defective allele was detected in this patient, the value of MR was 0.81 . For the distribution of metoprolol/ $\alpha$-hydroxymetoprolol MRs see Figure 1.

\section{Part two}

Metoprolol concentrations and demography in genotype, phenotype groups

Thirty patients were included in this second part of the study. The same controlled released formulation of metoprolol (Betaloc SR, AstraZeneca, UK) was prescribed to all of these patients. Daily dose ranged between 100-200 mg. Metoprolol serum concentrations varied extensively between patients, even among patients with the same daily dose. After metoprolol concentrations were normalized for dose per $\mathrm{kg}$ the variation was less pronounced, however still evident (Tab. 2). There was no significant difference in the daily metoprolol dose prescribed and dose per body weight between both the genotype and phenotype groups. A statistically significant difference was found in the median age ( 69 versus 52 years, $\mathrm{p}<0.01)$ between the genotype groups. The respective data are given in the Table 3.

\section{Metoprolol pharmacokinetic parameters and pharmacodynamics in relation to $P 4502 D 6$ genotype}

Metoprolol serum concentrations were normalized for the daily drug dose per body weight to compensate for individual

Tab. 3. Patients' demographic data in the genotype and phenotype groups.

\begin{tabular}{|c|c|c|c|c|}
\hline & \multicolumn{2}{|c|}{ Genotype } & \multicolumn{2}{|c|}{ Phenotype } \\
\hline & $\begin{array}{c}* 1 / * 1 \\
(\mathrm{n}=19)\end{array}$ & $\begin{array}{l}* 1 / \mathrm{DA} \\
(\mathrm{n}=11)\end{array}$ & $\begin{array}{l}\mathrm{MR}<1.0 \\
(\mathrm{n}=14)\end{array}$ & $\begin{array}{c}\text { MR 1.0-10.5 } \\
(\mathrm{n}=16)\end{array}$ \\
\hline Age (years) & $52(21-73)$ & $69(32-80)+$ & $54.5(21-74)$ & $63(32-80)$ \\
\hline Weight $(\mathrm{kg})$ & $87.8(64.9-119.5)$ & $82.0(63.0-123.0)$ & $78.0(64.9-123)$ & $90.8(63-119.5)$ \\
\hline Dose per body weight $(\mathrm{mg} / \mathrm{kg})$ & $2.11(0.95-3.08)$ & $1.59(0.97-2.82)$ & $2.19(1.04-3.08)$ & $1.96(0.95-2.82)$ \\
\hline
\end{tabular}

Median and range, Mann-Whitney test, ${ }^{+} \mathrm{p}<0.01$, DA - defective allele, MR - metoprolol/ $\alpha$-hydroxymetoprolol metabolic ratio 


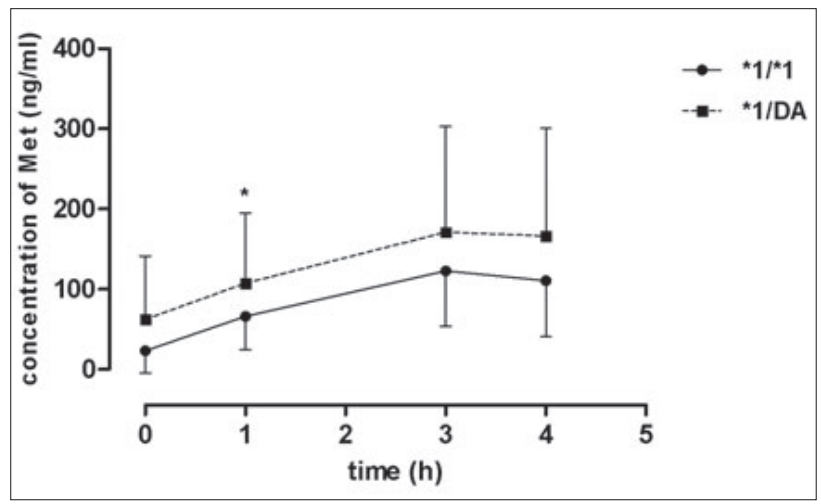

Fig. 2. Normalized metoprolol serum concentrations between two genotype groups - subjects with $2(n=19)$ and $1(n=11)$ functional P450 2D6 allele, ( $<<0.05$, for intergroup differences, Mann-Whitney test), DA - defective allele, Met - metoprolol.

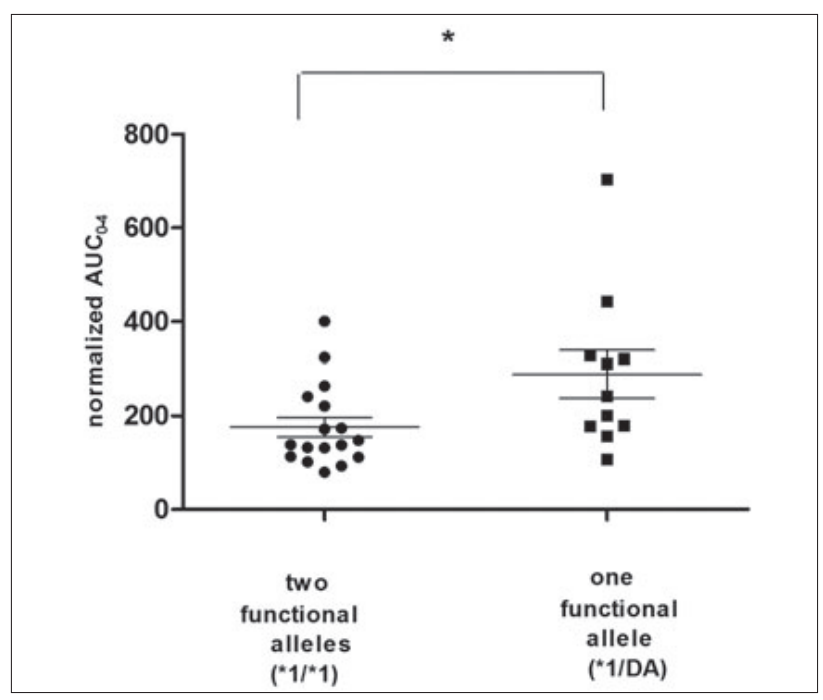

Fig. 3. Distribution of normalized metoprolol $\mathrm{AUC}_{0-4}$ between two genotype groups - subjects with $2(n=19)$ and $1(n=11)$ functional P450 2D6 allele ( $<<0.05$, for intergroup differences, Mann-Whitney test), DA - defective allele.

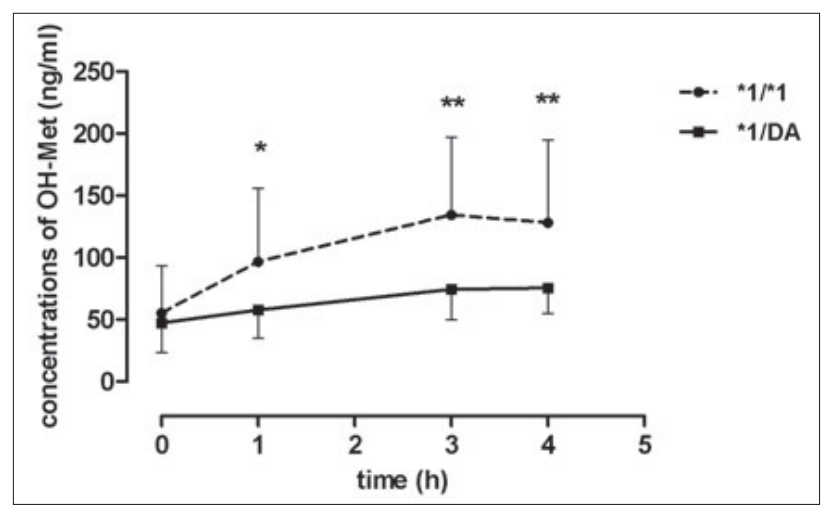

Fig. 4. $\alpha$-hydroxymetoprolol serum concentrations between two genotype groups - subjects with $2(n=19)$ and $1(n=11)$ functional P450 2D6 allele, $\left({ }^{*} \mathbf{p}<0.05,{ }^{* *} \mathbf{p}<0.01\right.$, for intergroup differences, Mann-Whitney test), DA - defective allele, $\mathrm{OH}$-Met $=\alpha$-hydroxymetoprolol.

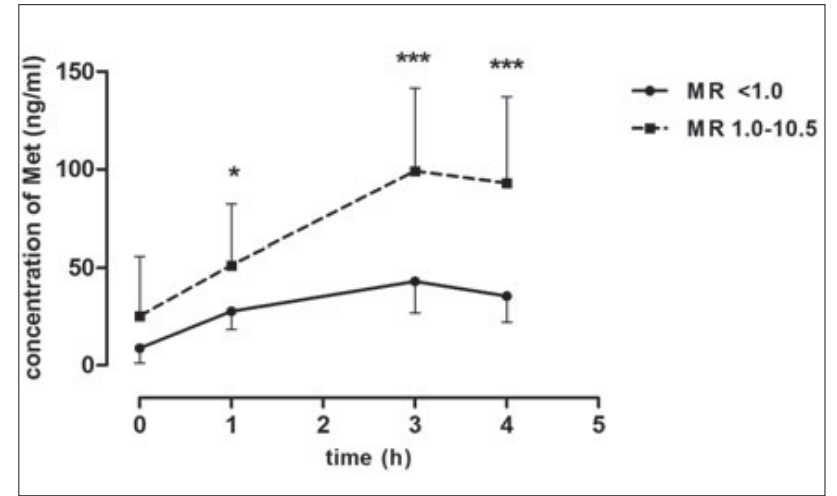

Fig. 5. Normalized metoprolol serum concentrations between two phenotype groups: $M R<1.0(n=14)$ and MR 1.0-10.5 $(n=16)(* p<0.05$, $* * * \mathbf{p}<\mathbf{0 . 0 0 0 1}$, for intergroup differences, Mann-Whitney test), MR metoprolol/a-hydroxymetoprolol metabolic ratio.

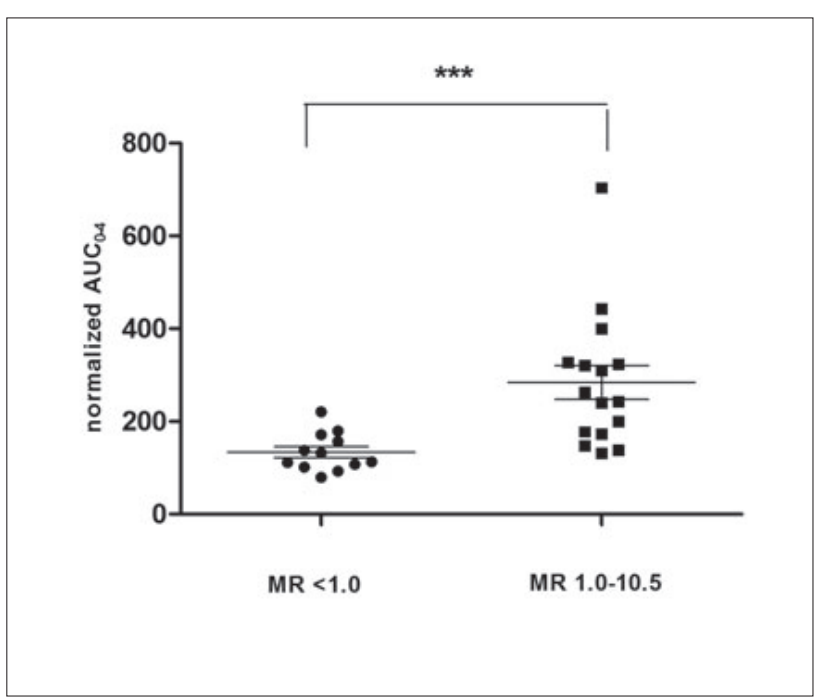

Fig. 6. Distribution of normalized metoprolol AUC0-4 between two phenotype groups: $M R<1.0(n=14)$ and $M R 1.0-10.5(n=16)(p<0.0001$, for intergroup differences, Mann-Whitney test), MR - metoprolol/ahydroxymetoprolol metabolic ratio.

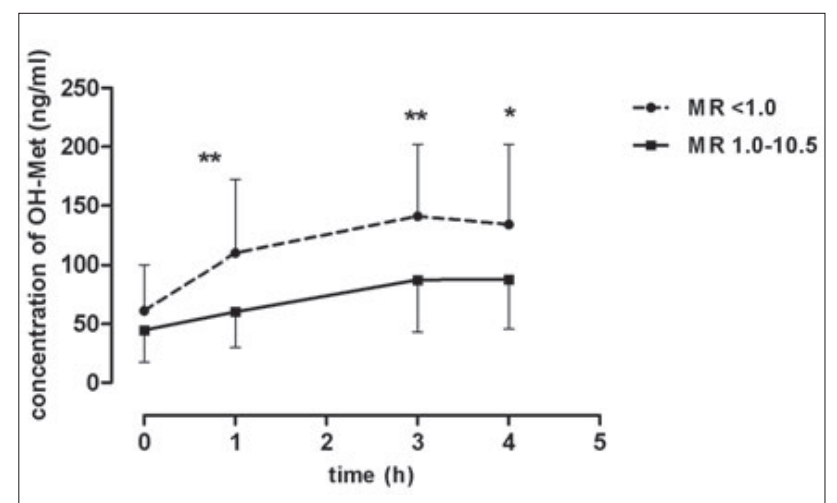

Fig. 7. $\alpha$-hydroxymetoprolol serum concentrations between two phenotype groups: $M R<1.0(n=14)$ and MR 1.0-10.5 $(n=16)\left({ }^{*} p<0.05,{ }^{* *} p<0.01\right.$, for intergroup differences, Mann-Whitney test), OH-Met $=\alpha$-hydroxymetoprolol, MR - metoprolol/a-hydroxymetoprolol metabolic ratio. 


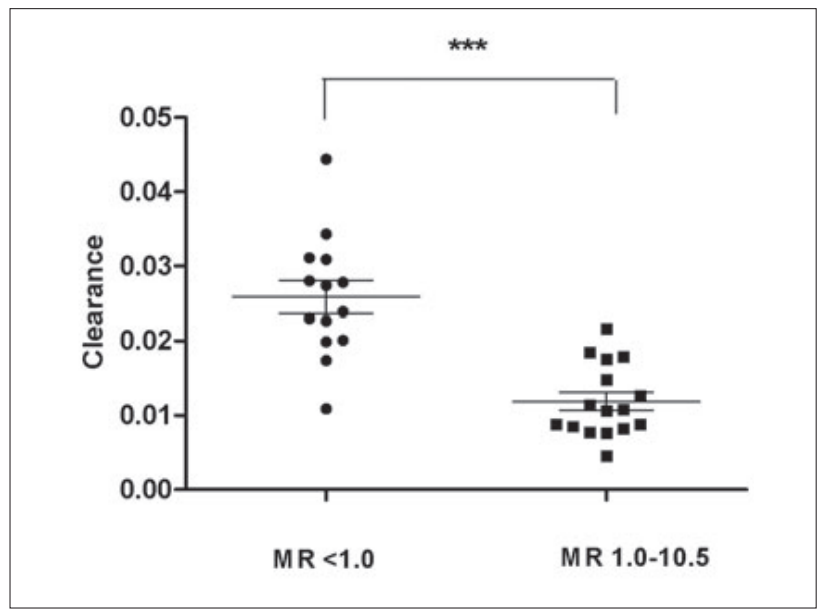

Fig. 8. Distribution of metoprolol oral clearance between two phenotype groups: $M R<1.0(n=14)$ and MR 1.0-10.5 $(n=16)(p<0.0001$, for intergroup differences, Mann-Whitney test), MR - metoprolol/ $\alpha$ hydroxymetoprolol metabolic ratio.

doses prescribed and the body masses. Heterozygous EMs $(n=11)$ for the defective allele exhibited 1.5-2.5-fold higher median normalized metoprolol serum concentrations than homozygous EMs $(n=19)$. The differences were not statistically significant except for the normalized metoprolol serum concentration 1 hour after metoprolol dose $(p<0.05)$ (Fig. 2). The 1.8-fold higher median normalized metoprolol $\mathrm{AUC}_{0-4}$ in heterozygous EMs (median 243.3, range 107.7-704.3) compared to patients without any defective allele (median 138.6, range 79.7-400.1) was observed $(\mathrm{p}<0.05)$ (Fig. 3). As expected, serum concentrations of the metabolite, $\alpha$-hydroxymetoprolol were lower in heterozygous EMs than in homozygous EMs. The differences were significant $(\mathrm{p}<0.05)$ except for the trough $\alpha$-hydroxymetoprolol concentrations (Fig. 4). Metoprolol/ $\alpha$-hydroxymetoprolol MR was 2.4 -fold higher in patients with the presence of one defective allele (median 1.91, range 0.67-6.60) compared to patients with no defective allele (median 0.81 , range $0.32-4.17), \mathrm{p}<0.05$. The oral clearance of metoprolol was about 1.8-fold higher in patients without any defective allele compared to patients with one defective allele (median 0.0201, range $0.0077-0.0444$ versus median 0.0114 , range $0.0045-0.0311$ ), however the difference did not reach a statistical significance.

Resting heart rate was used as a measure of metoprolol pharmacodynamics. Blood pressure was also registered, but served only as a measure of clinical effect of antihypertensive medication. A trend towards a lower median resting heart rate before metoprolol intake was observed in patients with inherited one defective allele when compared to patients without any defective allele (median 60 , range $47-83$ versus median 68 , range $58-113$, $\mathrm{p}=0.0738$ ).

\section{Metoprolol pharmacokinetic parameters and pharmacodynamics in relation to $P 4502 D 6$ phenotype}

Patients were classified into the two groups according to their phenotype, those with a value of metoprolol/ $\alpha$-hydroxymetoprolol $\mathrm{MR}<1.0(\mathrm{n}=14)$ and with MR 1.0-10.5 (n=16). In accordance with
MR, normalized metoprolol serum concentrations were 1.4-2.8fold higher in patients with MR 1.0-10.5. The differences were statistically significant except for the normalized metoprolol serum concentration before metoprolol intake $(\mathrm{p}<0.0001)$ (Fig. 5). A 2-fold higher median normalized metoprolol $\mathrm{AUC}_{0-4}$ was observed in patients with MR 1.0-10.5 (median 253.6, range 131.5704.3) compared to patients MR $<1.0$ (median 122.6, range 79.7220.7) $(\mathrm{p}<0.0001)$ (Fig. 6). Serum concentrations of metabolite, $\alpha$-hydroxymetoprolol, were lower in patients with MR 1.0-10.5 than in patients with MR $<1.0$. The differences were significant $(p<0.05)$ except for the trough $\alpha$-hydroxymetoprolol concentrations (Fig. 7). The oral clearance of metoprolol was about 2.4-fold higher in patients with $\mathrm{MR}<1.0$ compared with patients with MR 1.0-10.5 (median 0.0257, range 0.0109-0.0444 versus median 0.0107 , range 0.0045-0.0217) $(\mathrm{p}<0.0001)$ (Fig. 8).

A trend towards a lower median resting heart rate before metoprolol intake was observed in patients with MR 1.0-10.5 when compared to patients with MR $<1.0$ (median 61, range 47-83 versus median 69, range 59-113, $\mathrm{p}=0.0620$ ).

\section{Discussion}

We studied the enzymatic activity of P450 2D6 in patients on a long term-therapy with metoprolol, using metoprolol as a probe substrate and compared these results to P450 2D6 genotype and phenotype. Significant differences existed in metoprolol disposition in relation to $\mathrm{P} 450$ 2D6 genotype and phenotype during longterm metoprolol therapy. However, the differences were more expressed between the phenotype groups.

Wide interindividual variations in metoprolol serum concentrations have been observed in our and also previous studies $(16,24)$. After metoprolol concentrations were normalized for dose per $\mathrm{kg}$, the variation was less pronounced, however still evident. It thus appears that other factors than the dose and the patient weight play an important role in the variation. A great variability in MR metoprolol/ $\alpha$-hydroxymetoprolol was observed in our patients. Contrary to genotyping, phenotyping revealed three patients with a PM phenotype. One of these patients was simultaneously taking antiarrhythmic agent propafenone, the second one antidepressive agent sertraline, agents known to inhibit P450 2D6 activity. Two to five-fold increase in the steady-state levels of metoprolol has been described in patients after propafenone was added to the metoprolol therapy even with an occurrence of adverse effects in some patients $(25,26)$. Discontinuation of propafenone therapy switched the patient's phenotype from PM to EM (26). A less pronounced inhibitory effect was described with sertraline, which increased metoprolol AUC by $48 \%$ and $67 \%$ (27). It is questionable whether the PM phenotype in this latter patient was caused solely by the inhibitory effect of sertraline or the presence of other defective P450 2D6 alleles not determined in our department of genetics might play the role.

The variations in metoprolol plasma concentrations have been mainly associated with variations in metabolism due to genetic polymorphism (13-17). We have demonstrated that significant differences may exist between individuals homozygous for the 
wild type P450 2D6 gene and heterozygous carriers of one variant allele. Clinically significant differences in metoprolol disposition have also been demonstrated in a study between homozygous and heterozygous P450 2D6 healthy volunteers. Metoprolol AUC and minimum steady-state metoprolol concentrations were more than 2 times higher in heterozygous individuals (28). In contrast to these findings, no significant differences in MR and metoprolol plasma concentration were found between the heterozygous EMs and homozygous EMs in the study investigating the consequences of P450 2D6 genotype on metoprolol disposition in patients on long term-therapy (29). The discrepancy could be due to the contribution of *IM alleles (e.g.*41, *9, etc.) (4), that were not tested in our and the above-mentioned study. *IM alleles were significantly associated with higher plasma concentrations of metoprolol and metabolic ratio if inherited in conjunction with a defective allele (29). However, more distinct differences in metoprolol disposition were observed when P450 2D6 phenotype instead of the genotype was taken into consideration. Phenotyping can determine the exact enzymatic activity as it also reflects non-genetic factors (10). Besides drug interactions, the effect of age, gender might play a certain role in metabolic activity. Most of our patients included in this study were of older age, when the pre-systemic elimination might be reduced due to changes in hepatic blood flow, volume of distribution (30). Furthermore, women have been found to have higher metoprolol exposure than men (31). Metoprolol serves as one of the probe drugs for P450 2D6 phenotyping. The metabolic ratio of metoprolol over its metabolite $\alpha$-hydroxymetoprolol in plasma 3 hours after metoprolol administration has been validated under standard conditions for the measurement of enzyme activity of P450 2D6 in vivo (11). Thus, the use of metoprolol MR based on a single blood sample in patients routinely treated with metoprolol would provide a simple alternative for determination of metabolic activity (32).

Metoprolol has a dose-dependent effect, the beta 1 -blocking effect increases with increasing daily doses of metoprolol up to a

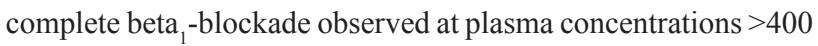
$\mathrm{nmol} / \mathrm{l}$ (about $107 \mathrm{ng} / \mathrm{ml}$ ). However, $30 \%$ of the maximum effect is necessary for a clinically significant effect, this limit was observed at metoprolol plasma concentration of $45 \mathrm{nmol} / 1$ (about $12 \mathrm{ng} / \mathrm{ml}$ ) (33). In a population-based study, a significantly lower adjusted heart rate was seen in IMs $(* 1 / * 4)$ compared to EMs, however, the most distinguished effect was observed in PMs (34). Similarly, a significantly higher mean reduction in resting heart rate measured before metoprolol dose administration was observed in heterozygotes for a defective allele than in EMs (28). In contrast, in a study examining the effect of P450 2D6 genotype in patients with systolic heart failure, no differences in clinical effect were found between the genotype groups (35). In our study, metoprolol effect was determined by measuring the resting heart rate. A trend towards a lower median resting heart rate was observed in patients with higher metoprolol concentrations (patients with inherited one defective allele and with MR 1.0-10.5), this trend was observed only at metoprolol trough concentrations. The lack of difference in resting heart rate after metoprolol administration might be caused by an increase in metoprolol concentrations above the limit that is necessary for clinically significant effect (33). Some of our patients achieved maximum metoprolol serum concentrations that were several-fold higher then that observed for complete beta ${ }_{1}$ blocking effect. It is thus questionable whether these high metoprolol concentrations are required for the optimal clinical effect in these patients and whether the patients might profit from lower dose reducing the risk of adverse effects (36).

We are aware of the limitations of our study. The number of patients included in our study was quite low. However, we tried to include the most homogenous sample with respect to metoprolol dose and to metoprolol preparation that could contribute to differences in metoprolol pharmacokinetic parameters. Secondly, our patients were only genotyped for three defective alleles that are responsible for almost all PM genotype, thus further stratification of patients to more genotype groups was not possible.

In conclusion, we observed a significant variation in metoprolol disposition in hypertensive patients. The effect of $\mathrm{P} 450$ 2D6 genetic polymorphism is an important factor in metoprolol disposition. However, one should also remember the role of nongenetic factors. Age, gender and hepatic disorders can modify the metabolic activity. The influence of concomitant medication on metabolic activity is a well-recognised factor for genotypephenotype discordance that may even lead to a transformation of a phenotype. Thus, apart from genotyping, phenotyping provides a valuable method in determining the enzymatic activity and in optimising metoprolol therapy.

\section{References}

1. Anzenbacher P, Anzenbacherová E. Cytochromes P450 and metabolism of xenobiotics. Cell Mol Life Sci 2001; 58 (5-6): 737-747.

2. Daly AK. Pharmacogenetics of the cytochrome P450. Curr Top Med Chem 2004; 4 (16): 1733-1744.

3. Eichelbaum M. Polymorphic oxidation of debrisoquine and sparteine. Prog Clin Biol Res 1986; 214: 157-67.

4. http://www.cypalleles.ki.se/cyp2d6.htm

5. Zanger UM, Raimundo S, Eichelbaum M. Cytochrome P450 2D6: overview and update on pharmacology, genetics, biochemistry. Naunyn Schmiedeberg's Arch Pharmacol 2004; 369 (1): 23-37.

6. Llerena A, Dorado P, Peňas-Lledó EM. Pharmacogenetics of debrisoquine and its use as a marker for CYP2D6 hydroxylation capacity. Pharmacogenomics 2009; 10 (1): 17-28.

7. Bertilsson L. Geographical/Interracial differences in polymorphic drug oxidation. Clin Pharmacokinet 1995; 29 (3): 192-209.

8. Aklillu E, Herrlin K, Gustafsson LL, Bertilsson L, Ingelman-Sundberg M. Evidence for environmental influence on CYP2D6-catalysed debrisoquine hydroxylation as demonstrated by phenotyping and genotyping of Ethiopians living in Ethiopia or in Sweden. Pharmacogenetics 2002; 12 (5): 375-383.

9. Zourkova A, Hadasova E. Paroxetine-induced conversion of cytochrome P450 2D6 phenotype and occurrence of adverse effects. Gen Physiol Biophys 2003; 22: 103-113.

10. Frank D, Jaehde U, Fuhr U. Evaluation of probe drugs and pharmacokinetic metrics for CYP2D6 phenotyping. Eur J Clin Pharmacol 2007; 63 (4): 321-333. 
11. Sohn DR, Kusaka M, Shin SG, Jang IJ, Chiba K, Ishizaki T. Utility of a one-point (3-hour postdose) plasma metabolic ration as a phenotyping test using metoprolol in two East Asian populations. Ther Drug Monit 1992; 14 (3): 184-189.

12. Ďuricová J, Grundmann M. Beta-blokátory. Čes Slov Farm 2009; 58 (2): 60-66.

13. McGourty JC, Silas JH, Freestone S, Ramsay LE, Tucker GT, Woods HF et al. Metoprolol metabolism and debrisoquine oxidation polymorphism - population and family studies. Br J Clin Pharmacol 1985; 20 (6): 555-566.

14. Silas JH, McGourty JC, Lennard MS, Tucker GT, Woods HF. Polymorphic metabolism of metoprolol: clinical studies. Eur J Clin Pharmacol 1985; 28 Suppl: 85-88.

15. Lennard MS, Silas JH, Freestone S, Trevethick J. Defective metabolism of metoprolol in poor hydroxylators of debrisoquine. Br J Clin Pharmacol 1982; 14 (2): 301-303.

16. Ismail R, The LK. The relevance of CYP2D6 genetic polymorphism on chronic metoprolol therapy in cardiovascular patients. J Clin Pharm Ther 2006; 31 (1): 99-109.

17. Nozawa T, Taguchi M, Tahara K, Hashimoto $Y$, Igarashi N, Nonomura M et al. Influence of CYP2D6 genotype on metoprolol plasma concentration and $\beta$-adrenergic inhibition during long-term treatment. J Cardiovasc Pharmacol 2005; 46 (5): 713-720.

18. Wuttke H, Rau T, Heide R, Bergmann K, Böhm M, Weil J et al. Increased frequency of cytochrome P450 2D6 poor metabolizers among patients with metoprolol-associated adverse effects. Clin Pharmacol Ther 2002; 72 (4): 429-437.

19. Fux R, Mörike K, Pröhmer AM, Delabar U, Schwab M, Schaeffeler $\mathbf{E}$ et al. Impact of CYP2D6 genotype on adverse effects during treatment with metoprolol: A prospective clinical study. Clin Pharmacol Ther 2005; 78 (4): 378-387.

20. Peřinová I, Ďuricová J, Brozmanová H, Kacířová I, Grundmann M. Determination of metoprolol and its metabolite $\alpha$-hydroxymetabolite in serum by HPLC method with fluorescence detection. Čes Slov Farm 2008; 57 (6): 254-259.

21. Roijers JFM, Jansen-Houtepen L, Jakobs BS, van Wijk EM. Detection of the CYP2D6*6 allele by LightCycler real-time PCR. Ned Tijdschr Klin Chem Labgeneesk 2007; 32 (4): 270-272.

22. Jonkers RE, Koopmans RP, Portier EJ, van Boxtel CJ. Debrisoquine phenotype and the pharmacokinetics and beta-2-receptor pharmacodynamics of metoprolol and its enantiomers. J Pharmacol Exp Ther 1990, 256 (3): 959-968.

23. Buzková H, Pechandová K, Slanar O, Perlík F. Frequency of single nucleotide polymorphisms of CYP2D6 in the Czech population. Cell Biochem Funct 2008; 26 (1): 76-81.
24. Bengtsson C, Johnsson G, Regårdh CG. Plasma levels and effects of metoprolol on blood pressure and heart rate in hypertensive patients after an acute dose and between two doses during long-term treatment. Clin Pharmacol Ther 1975; 17 (4): 400-408.

25. Wagner F, Kalusche D, Trenk D, Jähnchen E, Roskamm H. Drug interaction between propafenone and metoprolol. Br J Clin Pharmac 1987; 24 (2): 213-220.

26. Duricova J, Perinova I, Jurckova N, Kacirova I, Grundmann M. Clinically important interaction between metoprolol and propafenone. Accepted to Can Fam Physician (in Press).

27. Preskorn SH, Greenblatt DJ, Flockhart D, Luo Y, Perloff ES, Harmatz JS et al. Comparison of duloxetine, escitalopram, and sertraline effects on cytochrome P450 2D6 function in healthy volunteers. J Clin Psychopharmacol 2007; 27 (1): 28-34.

28. Koytchev R, Alken RG, Vlahov V, Kirkov V, Kaneva R, ThyroffFriesinger $\mathbf{U}$ et al. Influence of the cytochrome P4502D6*4 allele on the pharmacokinetics of controlled-release metoprolol. Eur J Clin Pharmacol 1998; 54 (6): 469-474.

29. Rau T, Heide R, Bergmann K, Wuttke H, Werner U, Feifel $N$ et al. Effect of the CYP2D6 genotype on metoprolol metabolism persists during long-term treatment. Pharmacogenetics 2002; 12 (6): 465-472.

30. Regardh CG, Johnsson G. Clinical pharmacokinetics of metoprolol. Clin Pharmacokinet 1980; 5 (6): 557-569.

31. Luzier AB, Killian A, Wilton JH, Wilson MF, Forrest A, Kazierad DJ. Gender-related effects on metoprolol pharmacokinetics and pharmacodynamics in healthy volunteers. Clin Pharmacol Ther 1999; 66 (6): 594-601.

32. Ďuricová J, Peřinová I, Kacířová I, Grundmann M. Comparison of metoprolol/ $\alpha$-hydroxymetoprolol metabolic ratio after a single dose and in steady state. Čes Slov Farm 2010; 59 (5): 222-226.

33. Abrahamsson B, Lücker P, Olofsson B, Regårdh CG, Sandberg A, Wieselgren I et al. The relationship between metoprolol plasma concentration and beta 1-blockade in healthy subjects: a study on conventional metoprolol and metoprolol CR/ZOK formulations. J Clin Pharmacol 1990; 30 (2 Suppl): S46-54.

34. Bijl MJ, Visser LE, van Schaik RH, Kors JA, Witteman JC, Hofman A et al. Genetic variation in the CYP2D6 gene is associated with a lower heart rate and blood pressure in $\beta$-blocker users. Clin Pharmacol Ther 2009; 85 (1): 45-50.

35. Sharp CF, Gardiner SJ, Jensen BP, Roberts RL, Troughton RW, Lainchbury JG et al. CYP2D6 genotype and its relationship with metoprolol dose, concentrations and effect in patients with heart failure. Pharmacogenetics J 2009; 9 (3): 175-184.

Received March 17, 2011. Accepted June 16, 2011. 